\title{
MITOLOGÍA CLÁSICA Y RETÓRICA EN GODOFREDO DE VINSAUF
}

\author{
HeLENa GuZmán \\ UNED. Madrid \\ Ana M. ${ }^{\text {a Calvo Revilla }}$ \\ San Pablo CEU. Madrid
}

\section{RESUMEN}

En el presente trabajo se efectúa un análisis de las posibles fuentes literarias empleadas por el autor de la Poetria nova, Godofredo de Vinsauf, en los numerosos ejemplos de los que se sirve para exponer su doctrina sobre la composición literaria, que encuentra sus raíces en las dos ciencias tradicionales del discurso: retórica y gramática.

La Poetria nova de Godofredo de Vinsauf ', compuesta entre los años 1209 y 1215 , constituye la primera exposición completa sobre el arte poética

1 Cf. E. FARAL, Les Arts Poétiques du XIle et du XIIle siècle. Champion. 1971, 197-262 [Ed. or., 1924]; A. Calvo Revilla, Los mecanismos dispositivos de la expresividad en la Poetria nova de Godofredo de Vinsauf. Tesis doct. inédita, Madrid, 2000, de donde se han tomado las traducciones aquí utilizadas; C. Ponce, Geoffroi de Vinsauf. La Poética Nueva. México: Universidad Nacional Autónoma de México, 2000. Para un estudio detenido de esta poética medieval, véase tam- 
de la época medieval, y permanece enmarcada dentro de uno de los grandes géneros retóricos medievales, el ars poetriae ${ }^{2}$; las artes poetriae fueron escritas durante un período de setenta y cinco años comprendido entre los siglos XII y XIII, por una serie de maestros de gramática europeos, que se consagraron a la tarea de ayudar a quienes desearan componer en prosa y en verso.

La Poetria nova consta de siete secciones, a lo largo de las cuales abarca de un modo sistemático y continuado el estudio de las cinco operaciones retóricas, mediante la formulación de preceptos y reglas: inventio, dispositio, elocutio, memoria y actio. Sigue el esquema de la retórica tradicional, en la cual se inspira como en una de sus fuentes primordiales, fundamentalmente en el Ars poetica de Horacio, también llamada la Poetria durante la Edad Media, y la Rhetorica ad Herennium ${ }^{3}$.

La Poetria nova asume los principios básicos de las dos principales ciencias del discurso que la Edad Media hereda de la Antigüedad clásica, la retórica y la gramática -ésta era entre las tres artes del trivium (gramática, retórica y dialéctica) la que gozaba de una posición privilegiada, asumiendo tanto el estudio del lenguaje como la enarratio poetarum, es decir, el comentario de los textos literarios de los autores clásicos ${ }^{4}$ - . Nos hallamos ante la obra de una gramático que nos proporciona no sólo un extenso tratamiento de la materia, sino también numerosos ejemplos de cada uno de ellos.

Godofredo de Vinsauf va exponiendo su doctrina - con una clara intencionalidad instructiva - a través de numerosos exempla que aparecen diseminados a lo largo de la obra, en los cuales se sirve de los tópicos tradicionales,

bién A. Calvo Revilla, «Rasgos de oralidad en la Poetria nova de Godofredo de Vinsauf: un acercamiento a la memoria y actio/pronuntiatio». Tropelías 9-10, 1998-1999, 79-91; A. CALvo Rev1LLA, «El modelo retórico, entramado de la poética medieval: análisis de la Poetria nova de Godofredo de Vinsauf». Helmantica, 53, 2002, 281-307; A. Calvo Revilla, "Presencia de la poliacroasis en las artes poéticas medievales». Actas del III Congreso Hispánico de Latín Medieval, León, 2002, vol. I, 287-294. Véase también E. GAl.LO. The Poctria Nova and its Sources in Early Rhetorical Doctrine. The Hague-Paris. Mouton, 1971, 133.

2 Cf. D. KELLY, «The Scope of the Treatment of Composition in the Twelfth - and the Thirteenth-Century Arts of Poetry", Speculum, 41, 1966, 261-278; y también D. KELLY, "Theory of Composition in Medieval Narrative Poetry and Geoffrey of Vinsauf's Poetria Nova». Mediaeval Studies, 31, 1969, 117-148.

"Cf. M. C. Woods, «Classical Examples and References in Medieval Lectures on Poetic Composition", Allegorica, 10, 1989, 3-12, 3. Véase M. CAMARgo, «Toward a Comprehensive Art of Written Discourse: Geoffrey of Vinsauf and the Arts Dictaminis», Rhetoric $a, 6,2,1988,167$. 194.

${ }^{4}$ Cf. S. ReYnol.DS, Medieval Reading (grammar, rhetoric, and the classical text), Cambridge, Cambridge University Press, 1966, p. 11. Véase también J. J. Murphy, La Retórica en la Edad Media. Historia de la teoría de la retórica desde San Agustín hasta el Renacimiento. México, F. C. E., 1986, 145 [Ed. or., 1974]. 
que eran accesibles a los destinatarios de esta ars poetriae por tratarse de lugares comunes en la literatura medieval, y de temática variada (religiosa, histórica, literaria, mitológica, etc.). Este hecho tiene su punto de partida en la práctica educativa medieval, contenida en el curriculum gramatical: como es sabido, los estudiantes no se limitaban al estudio de los preceptos sino también a la práctica de la imitatio de modelos 5 , a través de la lectio o enarratio poetarum, es decir, del comentario de los textos literarios de los autores clásicos. Los gramáticos hacían uso de tales textos literarios, que pasaban a constituir una materia importante de estudio.

No podemos olvidar el enorme peso que ejerció la práctica de la retractatio ${ }^{6}$ entre los poetas latinos, más propicios a la imitación de los clásicos que a los ejercicios de invención literaria, a través de una labor de recreación novedosa de una materia dada.

Así, aunque en la Poetria nova no hay una referencia explícita al tipo concreto de materia que ha de elaborar el poeta, todo apunta a que sus reflexiones sobre la materia aluden al cultivo de la materia tradicional. Y, en este sentido, podemos reconocer en el pensamiento poético de Godofredo de Vinsauf, la defensa y el uso de una tradición textual en la que se encuentra una reserva tópica, de temática a desarrollar y a reelaborar artísticamente.

El autor, a lo largo de su exposición teórica, se va sirviendo de referencias literarias concretas, que utiliza a modo de ejemplos de su modus operandi. Buena parte de tales referencias pertenecen al ámbito de la Mitología Clásica, y en ocasiones también al de la propia historia de la Antigüedad grecolatina. Querríamos en este trabajo proceder a un análisis del uso que en esta obra se hace de tales materiales míticos e históricos, lo que a la postre abundará en una mayor y más precisa visión del conocimiento que se tenía en esa época del Mundo Clásico.

Podemos clasificar los ejemplos utilizados en la Poética en tres tipos teniendo en cuenta sus características formales: el primer grupo está formado por aquellos casos en los que el relato propiamente dicho de un mito está presente con una cierta extensión, es decir, aquellos en los que el poeta utiliza la narración más o menos completa de un mito. El segundo grupo lo componen aquellos ejemplos en los que se hace referencia a una escena o a un punto concreto

${ }^{5}$ Cf. S. Reynotos, Medieval Reading (grammar, rhetoric and the classical text), cit.: 11; $\mathbf{R}$. R. Bolgar. Classical Heritage and lts Beneficiaries, Cambridge, Cambridge University Press, 1963 [Ed. or., 1954], p. 210.

"Cf. R. MCKEON, «Literary Criticism and the Concept of Imitation in Antiquity», R. CRANE (ed.), Critics and Criticism Ancient and Modern. Chicago, The Chicago University Press, 1952, 147-175. 
del mito. Finalmente, el tercer grupo está constituido por las alusiones tópicas a una característica bien conocida del personaje mítico o histórico.

De otro lado, es evidente que todos los ejemplos se utilizan con una finalidad concreta dentro de la Poética. Iremos, pues, localizando cada ejemplo en el total de la obra y señalando cuál es su función.

\section{PRimer TIPO: DESARRollo AMPLio Del RELATO MÍtico}

En este primer grupo se engloban los pasajes en los que se cuenta un relato mítico de manera extensa. Sólo hay un ejemplo de este tipo. Se trata del mito de Minos, Androgeo y Escila.

Hagamos un breve resumen del mito: Androgeo es uno de los hijos que Minos tuvo con Pasifae. Era un excelente atleta, por lo que acudió a Atenas para participar en las competiciones organizadas por Egeo. Como venció a todos sus rivales, Egeo, receloso, lo mandó a luchar contra el toro de Maratón, ante el cual murió. Cuando Minos se enteró, reunió una flota para atacar Atenas y vengar así la muerte de su hijo. En el camino se apoderó de Mégara, sitio clave del Ática, gracias a la traición de Escila, hija del rey Niso: cuando Minos llegó a Mégara, Escila se enamoró profundamente de él y, tras conseguir la promesa de que se casaría con ella si le ayudaba a vencer a su padre, Escila cortó un cabello de púrpura que hacía invencible a Niso. Finalmente, Minos aterrado por el comportamiento de Escila, la ató a la proa de su nave donde se ahogó. El resto de la historia ya no nos interesa demasiado para nuestro propósito: Minos pidió ayuda a Zeus, quien envió hambre y peste a Atenas; para liberarse de esta plaga los atenienses debían pagar un tributo al rey Minos: siete jóvenes y siete doncellas para ser alimento del Minotauro, hijo de Pasifae.

Veamos primero el contexto del pasaje. En los versos 134 ss. Vinsauf se plantea el problema de las diferentes maneras que tiene un escritor de empezar un relato. En este punto de su tratado él establece tres tipos de dar comienzo a una narración: empezar por el principio, siguiendo un orden lineal temporal de los acontecimientos; o bien comenzar in media res, es decir, en medio del relato para luego, en un momento posterior, volver al momento anterior; finalmente, también se puede iniciar la narración por el final.

Vinsauf ejemplifica estos tres procedimientos sirviéndose del mito de Minos, Androgeo y Escila:

a) Si se empieza por el principio, según el orden natural, lo lógico es comenzar por el primer personaje, el rey Minos. El autor nos da una descripción del personaje hablando de sus cualidades: es fuerte, bien parecido, inteligente, 
buen orador y exquisito en sus costumbres; podríamos decir que es un individuo envidiable (Poetria nova vv. 158-65):

A parte de las cualidades naturales de la Fortuna, cuya abundancia fluye desbordándose, como si proviniera de un torrente, la naturaleza con otro esplendor aclara la gloria de Minos: la naturaleza equipa su cuerpo con una fuerza excepcional; embellece sus miembros con una extraña belleza. Al mismo tiempo ella madura el oro de su mente, la plata de su lengua: abrillanta cada detalle con perfección, derramando un dulzor extraordinario en su manera. Cuanta belleza conviene al rey igualmente se presenta en toda su naturaleza.

b) Si se empieza la historia por el final -en cuyo caso estamos, lógicamente, ante un ejemplo claro de un principio artificial desde la óptica retórica一, se hablará de Escila y de por qué se produjo su funesto desenlace: (Poetria nova vv. 166-72):

La revuelta de Escila engañó a Escila; con la misma herida con la que hirió fue herida: y la que traicionó a su padre, perdió aquello que deseaba; y, puesto que causó daño, sufrió un daño semejante. Una merecida venganza se volvió contra el autor del fraude con un fraude de intensidad semejante.

c) Por último, el comienzo in media res -un inicio retórico igualmente artificial- supone empezar con la historia de Androgeo y Egeo, parte intermedia del mito: Egeo siente envidia del joven Androgeo tanto por su edad como por su extraordinario valor y por los grandes elogios que recibe (Poetria nova vv. 173-9):

La envidia observando la mente y los años de Androgeo, ve en sus años un niño, en su mente a un anciano, porque con su mente senil el niño no dejaba percibir nada infantil. Empezó a serun desdichado de sus éxitos; puesto que su alabanza se encumbró muy alto. Androgeo es humillado desde esa altura. Puesto que así resplandece, lucha contra su propio destino y dispone su espíritu contra la edad que le corresponde.

Pero Vinsauf no se detiene en la determinación de estas tres posibilidades generales, sino que entra en una mayor precisión. Y, así, menciona la posibilidad de que se comience el relato por una sentencia. Lo que dará lugar, lógicamente, a una triple opción según el tipo general de comienzo por el que se ha- 
ya optado. Y acude de nuevo a este mito de Minos, Androgeo y Escila, para ejemplificar los diferentes tipos de sentencia-inicio:

a) Si el relato empieza por una sentencia referida a la parte inicial del relato, aquélla estará centrada en la figura de Minos. Ahora bien, al tratarse de una sentencia, esto es, un dicho general que encierra una moralidad, el autor remite no a las magníficas cualidades que se han visto en la primera descripción, sino a lo rápido que se puede producir la pérdida de esas virtudes, a la fugacidad de las pertenencias, tópico ya muy extendido: (Poetria nova vv. 181-4):

Lo que más se desea, más rápidamente se desvanece. Todo presagia la caida y la prosperidad está más dispuesta para la ruina. La cruel fortuna siempre presenta sus emboscadas con suavidad y la mejor fortuna repentinamente se da a la fuga.

b) Otra posibilidad es que la sentencia por la que se empieza, vaya referida a la parte media del relato. Ejemplificando con este mito, la mitad es la envidia que siente Egeo por la victoria del joven Androgeo, por lo que la sentencia trata de lo destructora que es la envidia (Poetria nova vv. 186-9):

La envidia, la peor de todas las cosas, es por completo un veneno mortal, bueno únicamente para el mal, absolutamente malvado contra la hondad. Cualquier decisión malévola se concibe de antemano en secreto y toda la amargura que se concibió se difunde abiertamente.

c) Finalmente, existe la sentencia centrada en el episodio final del mito: Escila tiene que ser castigada por la cruel traición a su padre, el mal se paga con mal (Poetria nova vv. 191-2):

Justa es la ley que devuelve dolor con dolor; la que devuelve el dolor a la persona de donde partió.

Tarea más ardua es determinar con precisión la fuente clásica de la que se sirvió Godofredo de Vinsauf. Es un lugar común la aceptación de Ovidio como fuente fundamental en la cultura literaria de la baja Edad Media y así, en nuestro caso es muy probable que Vinsauf conociera bien el relato de Ovidio, Metamorfosis VII 453-8 y, sobre todo, VIII 1-151. Pero no disponemos de referencias textuales concretas que nos garanticen una relación directa. Sin embargo, parece haber una mayor conexión con el resumen que se nos conserva en varios pasajes del Primer Mitógrafo Vaticano, en especial la descripción de Minos en el libro II ( $P M V 2,70,1.5)$ : 
El cretense Minos, cuya sola nobleza de nacimiento bastaría para establecer la gloria y la reputación, obtuvo un gran mérito por su apacibilidad de carácter, hasta el punto de que los hombres lo admiraban más por sus costumbres que por la autoridad de su linaje. Fue rey de Creta y llevaba una vida tan moderada que - esto es lo asombroso- aquellos sobre los que reinaba eran felices de tenerlo como soberano.

En esta descripción del Mitógrafo Vaticano tal vez sea posible ver un adelanto de la imagen más pormenorizada que nos da Vinsauf de Minos como un hombre afortunado, poseedor de todo tipo de bienes. $\mathrm{Y}$ a esto se añade que la mencionada enciclopedia mitográfica medieval también conoce el relato de Androgeo $(1,43,4.5)$ y el de Escila $(1,3,1.5)$.

\section{SEGUNDO TIPO: REFERENCIA A UNA ESCENA O PUNTO CONCRETO DE UN RELATO MÍTICO}

En este segundo grupo de menciones de la mitología clásica, la referencia es ya más breve. Normalmente se trata de alusiones a una escena concreta o a un punto determinado dentro de un mito dado.

\subsection{Mito de Jano}

El poeta menciona este personaje mitológico dentro de un ejemplo de apóstrofe. Situémonos en la obra: Vinsauf está describiendo cómo es posible alargar la narración de la composición —a amplificatio-, y una de las maneras posibles es el apóstrofe. El apóstrofe es una figura retórica que consiste en apartarse repentinamente del público normal para dirigir la palabra a otro segundo público elegido por el orador de manera sorprendente. Este segundo público puede estar formado por una persona o varias, ya estén presentes o ausentes, o por cosas.

Tras definir la realidad retórica del apóstrofe, pasa nuestro autor a ofrecernos un ejemplo, dentro del cual introduce una referencia al mito de Jano, con el que materializa la reflexión general teórica en que está inmerso (Poetria nova $v$ v. 277-91):

Apóstrofe, ponte en pie ante el hombre cuyo espíritu se alza bastante en medio de felices sucesos, y castígale así: ¿por qué tan grandes gozos perturban tu alma? Reprime tu aplauso dentro de un mode- 
rado límite y no prolongues sus límites más allá de lo justo; oh alma, desconocedora de los sucesos futuros, sé emuladora de Jano: mira hacia atrás y hacia delante si las cosas han salido bien. No te vuelvas a mirar el principio sino el final. Valora cada día por la puesta del sol. no por su salida. Para estar totalmente segura, teme lo que va a venir: aunque pienses que has vencido a todo, una serpiente se esconde entre la hierba. Ten presente el ejemplo de las sirenas: aprende de ellas que bajo el mejor aspecto siempre se guarda lo peor. No hay nada fiable en las cosas de este mundo: después de la miel sigue el veneno y una noche oscura cierra el paso al día, y las nubes a un cielo sereno. Aunque todos los asuntos de los hombres suelen sucederse felizmente, con la mayor ligereza acostumbran a volverse contrarios.

Lo que nos interesa especialmente es la alusión al dios Jano y a su capacidad de visión, aunque también hay una mención a las sirenas que veremos más adelante. Jano es uno de los dioses más antiguos del mundo romano, donde se le representa siempre de la misma forma: con dos caras contrapuestas, una que mira hacia delante y otra hacia atrás, exactamente como nos lo describe nuestro autor.

Ovidio en los Fastos nos hace una descripción que, incluso en algún punto, presenta cierto paralelismo textual con el pasaje mencionado de Vinsauf, lo que podría apoyar la hipótesis de que esta obra ovidiana le era bien conocida (Fastos I, 91 ss.):

eres el único entre los celestiales que ves lo que está a la espalda y lo que está delante.

Y, más adelante, en un diálogo entre el dios y el poeta, aquél se define como (Fastos I, 139 ss.):

... asi yo... alcanzo a ver a un tiempo la parte de Levante y la parte de Poniente.

A partir de este autorretrato de Jano se entiende bien la cita de Vinsauf: hay que vigilar todo, el pasado y el futuro, to que ha ocurrido y lo que va a acontecer para estar prevenido.

Pero, además, en el pasaje mencionado se habla de las Sirenas, que aquí son utilizadas en apoyo de esa reflexión general sobre la cautela como regla de vida. Las sirenas son genios divinos, mitad mujer, mitad aves; su principal característica es su melodioso y seductor canto, que atrae a los navegantes pero los lleva a la perdición. Esta visión negativa de las Sirenas arranca ya de la Odi- 
sea homérica y se extiende por toda la Antigüedad. En ocasiones, no obstante, encontramos alusiones menos críticas, como la que encontramos en Las Metamorfosis de Ovidio ${ }^{7}$, donde son presentadas como muchachas compañeras de Prosérpina antes de que ésta fuera raptada; y tras el rapto por parte de Plutón, las Sirenas pidieron a los dioses tener alas para poder ir en busca de la joven, pero conservaron el rostro de mujer y la voz humana para poder seguir con sus increíbles cantos. Por lo tanto, en esta ocasión Vinsauf prefirió la versión tradicional, negativa, frente a la ovidiana aludida.

\subsection{Mito de Apolo y Sibila}

Dentro de este mismo apartado de la apóstrofe, pasa Vinsauf a una cuarta posibilidad de uso de esta figura retórica (Poetria nova vv. 324-5): En tiempo del éxito, en tiempo del destino alegre, puede tu boca expresar estos presagios de luto futuro.

El autor comienza con una referencia a la prosperidad que vive Inglaterra bajo el reinado del rey Ricardo, pero acaba destacando el riesgo de confiar excesivamente en las fuerzas humanas, para arremeter a modo de colofón contra los métodos tradicionales de la adivinación: el hombre no es capaz de conocer el futuro, sólo Dios está capacitado para ello. Y a continuación da entrada a una amplia digresión sobre el mundo clásico, que en este caso representa lo pagano, centrándose en los tradicionales recursos adivinatorios a la par que mezcla indiscriminadamente el mundo mítico con el histórico (Poetria nova vv. 345-65):

Adiós a los presagios que iban a decirte cosas felices: descansas, sudarás; ríes, llorarás; te enriqueces, tendrás necesidad; floreces, te marchitarás; eres, apenas serás. Sin embargo esto ¿cómo vas a saberlo?, ¿qué vas a hacer?. ¿vas a escudriñar de oído los murmullos de las aves?, ¿o sus movimientos con la vista?, ¿o los hados a través de Apolo? Ahuyenta a los astrólogos. El augur es sordo, el agorero ciego y el adivino loco. Al hombre le es lícito conocer lo presente y sólo a Dios predecir el futuro. Que el antiguo error vuelva a su patria - su patria no está aquí y que el gentil padre de la mentira alimente a aquel al cual engendró, puesto que una confianza firme suprime de la luz de la Iglesia los tripodes de Febo y el trono de Sibila. Puedes predecir únicamente esto, que ningün poder puede ser duradero, que la fortuna ordena que la prosperidad dure poco. Si quieres ejem-

${ }^{7}$ En el libro V, vv. 552-63, se las menciona con aprecio como dolientes amigas de Prosérpina, y se las califica de doctae. 
plos, mira la suerte de tus antepasados. Aquella floreciente prosperidad de los anteriores se marchitó: Minos derribó a Atenas, el hijo de Atreo a Troya, y Escipión a las ciudades de la gran Cartago, pero muchos conquistaron Roma. La suerte del hado se transformó en poco tiempo. Corta es la distancia entre un augurio feliz y uno funesto. La noche es vecina del día. Estos ejemplos ajenos enseñan, pero a ti te enseñarán tus propios hados.

Para empezar, queda de manifiesto el conocimiento de Vinsauf del entorno mántico en el mundo antiguo, y de forma concreta la figura de Apolo y la Sibila con esa alusión a los trípodes del primero y el solio de la segunda. Pero también es oportuno destacar su familiaridad con esa característica típica de la ceguera de los adivinos míticos, como Tiresias, que, a pesar de no ver con los ojos del cuerpo, son capaces sin embargo de contemplar el futuro, para los demás incierto.

Tras ese rechazo del mundo de la adivinación pagana, llega Vinsauf a la reflexión general: la felicidad de los humanos es pasajera, máxima que arranca realmente de las primera etapas de la cultura griega y será una de las muchísimas herencias que va a recibir el Cristianismo de la Antigüedad Clásica. Y esta reflexión la materializa en la pérdida de poder y destrucción de las cuatro grandes ciudades del mundo: Atenas, Troya, Cartago y Roma, sólo que, indiscriminadamente, pasa del plano mítico al histórico, lo que nos pone de manifiesto cómo la tradición cultural del Mundo Clásico había experimentado un proceso de idealización que borraba los límites entre la realidad y la ficción. Más aún: el mundo griego está claramente alejado, y las alusiones a él son las míticas (Minos destruye Atenas; los Atridas, Troya), aunque se ponen en el mismo plano de historicidad que las menciones romanas, indiscutiblemente históricas (Cartago, tomada por Escipión el año 146 a. C.; y Roma, víctima de numerosos ataques en su historia).

\subsection{Mito de Faetón}

Nuestro autor pasa más abajo a explicar un nuevo recurso retórico para desarrollar más el tema en cuestión: la prosopopeya, es decir, la atribución a las cosas inanimadas o abstractas de acciones y cualidades propias de seres anjmados, o a los seres irracionales las del hombre (Poetria nova vv. 461-3): Ven. oh prosopopeya, quinta ayuda, a extender aún más el discurso. A quien no tiene el poder de hablar, dale el privilegio de hablar y que la licencia le permita el lenguaje. 
Para ejemplificar este elemento retórico, el poeta utiliza el mito de Faetón. Faetón es hijo del Sol (Helios) y de la oceánide Clímene. Él no supo quién era su padre hasta que llegó a la adolescencia, y entonces el muchacho pidió a su padre que le dejara conducir su carro. El Sol, no muy convencido, finalmente accedió no sin hacerle antes innumerables indicaciones. Faetón empezó por el camino trazado en la bóveda celeste, pero se asustó al ver la altura que alcanzaba y comenzó a dar violentas sacudidas, tan pronto bajaba mucho por lo que casi incendiaba la tierra, como subía demasiado, por todo lo cual los astros se quejaron a Zeus. Éste, para evitar una perturbación total, fulminó a Faetón, precipitándolo en el río Erídano.

Vinsauf lo presenta de esta forma (Poetria nova vv. 464-6):

Así, la tierra, tras conocer las bocanadas de vapor de Faetón se quejó a Júpiter: así Roma. con los cabellos despeinados, se quejó con lacrimosa voz de la muerte de César.

Vuelve nuestro autor a mezclar lo histórico (Roma-César) con lo mítico (Tierra-Faetón), lo que confirma la sugerencia que hacíamos más arriba a este respecto.

Ahora bien, la alusión al mito de Faetón da pie a un par de comentarios. En primer lugar, es interesante destacar cómo en la tradición retórica se ha convertido en un recurso artificial lo que en la más pura tradición mítica era una realidad natural: la Tierra, en los relatos míticos, era un personaje tan real e individual como los otros seres del imaginario, por lo que tenía la posibilidad de hablar como ellos, como podemos observar en múltiples pasajes. Pero en un momento dado, cuando se ha perdido la mentalidad mítica y la Tierra se ha convertido en la realidad material que conocemos, la especulación estilísticoretórica re-crea, ahora con pretensiones puramente literarias, un recurso muy antiguo.

En segundo lugar, y ahora desde la óptica de la indagación de las posibles fuentes conocidas y utilizadas por Vinsauf, disponemos en este caso de un paralelismo interesante en Las Metamorfosis ovidianas, lo que confirma, en esta ocasión de forma prácticamente irrefutable, que Vinsauf conocía bien esta obra mitográfica latina.

Ovidio describe con pormenor el mito de Faetón en Metamorfosis II 1400: el primer encuentro con su padre, la petición de conducir su carro, la negativa inicial del Sol, su posterior consentimiento y sus consejos, el accidentado galope de Faetón y el fatal desenlace. Y en un momento determinado (Metamorfosis II, 272-303) hace intervenir a la Tierra de una forma que nos recuerda cabalmente la alusión de Vinsauf: 
Mas la Tierra..., aunque desecada ... se puso la mano sobre la frente ... y con su voz augusta habló así: "Si ésta es tu voluntad y si yo lo he merecido, ¿por qué, oh el más alto de los dioses, se hacen esperar tus rayos? ...» —el calor le oprimía la boca-Así habló la Tierra; y no pudo seguir tolerando los ardores...

\subsection{Mito de Aurora}

Más adelante (Poetria nova vv. 559-61) Vinsauf sugiere la descripción como recurso retórico para hacer la obra más extensa: Como séptimo método de amplificación de la obra, sigue la descripción, repleta de palabras. Pero, aunque la descripción sea amplia, procura que sea agradable: que sea en la misma medida vistosa y extensa.

Para esta figura estilística Vinsauf propone, entre otros ejemplos, la descripción del encanto femenino: primero la belleza del rostro, luego la del cuerpo. Y en un momento dado (Poetria nova v. 576s.), para aludir a la belleza ideal de las mejillas, recurre a la semejanza con Aurora, ese personaje mítico al que, ya desde Homero, se aplica sistemáticamente la tonalidad cromática del rosa (Aurora la de rosáceos dedos, repite una y otra vez Homero sin desánimo):

... émula de Aurora sea la faz, ni rubicunda ni pálida, sino con uno y otro color al tiempo y no con uno solo de los dos.

Dentro de esta larguísima tradición Ovidio no es una acepción, y nuevamente en sus Metamorfosis, especialmente en VII 705 al narrar el episodio de Céfalo y Procris, Aurora es descrita como admirable por su rosáceo rostro.

\subsection{Mitos de Júpiter}

Júpiter y su amplio catálogo de empresas amorosas no iban, lógicamente, a quedar fuera del repertorio de referencias a la Mitología Clásica. Así, dentro del ya aludido pasaje dedicado por Vinsauf a la descripción como recurso para la ampliación de la narración, incluye una amplia alusión a los diversas aventuras amorosas del rey de los dioses (Poetria nova vv. 618-26):

Si en otros tiempos Júpiter la hubiese visto, ni transformado en Anfitrión habría jugado con Alcmena, ni habría asumido la apariencia de 
Diana para desflorarte a ti, Calisto; ni habría engañado a Ío con una nube, ni a Antiopa con un sátiro, ni a la nacida de Agenor con un toro, ni a ti, Mnemósina, con un pastor, ni habría engañado a la engendrada por Asopo con fuego, o a la Deoida con una serpiente, o a Leda con un cisne, o a Dánae con oro. Rendiría culto a ésta sola y a todas vería en ella.

Como podemos ver hace un recorrido por muchos de los episodios amorosos que Júpiter tuvo con mujeres mortales. Todos estos mitos tienen algo en común: los protagonistas, ya sea el dios o las mujeres a las que se une, en casi todos estos mitos sufren una transformación para facilitar la unión; aunque también hay otros paralelismos en todos ellos: la belleza de la protagonista y su resistencia a unirse con el dios. En tales circunstancias, sería lógico pensar que, si en estos mitos se cuentan o bien transformaciones del dios o de las mortales, el poeta se haya basado en Las Metamorfosis de Ovidio. Y, efectivamente, así sucede, pero en esta ocasión el paralelismo llega mucho más lejos: en VI 104-14 Ovidio nos describe el manto que ha tejido Aracne en su competición con Palas, y el poeta nos va narrando los diversos episodios recogidos en la tela; pues bien, sorprendentemente encontramos que agrupa prácticamente los mismos temas que luego Vinsauf va a mencionar al hablar del ornato mencionado, lo que deja sin lugar a dudas que nuestro autor tenía bien presente la obra ovidiana cuando decidía introducir una referencia a la Mitología Clásica:

La Meónide (Aracne) dibuja a Europa engañada por la apariencia de toro: se hubiera creido que era un verdadero toro, un mar verdadero. Europa parecía dirigir su mirada a la tierra que había dejado y temer el contacto con el agua que saltaba junto a ella y encoger los pies asustados. También hizo que Asteria estuviera sujeta por un águila que luchaba, hizo que Leda estuviera acostada bajo las alas de un cisne; añadió cómo, oculto bajo la apariencia de Sátiro, llenó Júpiter de prole gemela a la bella Nicteida (Antíopa), cómo fue Anfitrión cuando se adueñó, Tirintia (Alcmena), de ti, cómo siendo de oro engañó a Dánae, siendo fuego a la Asópida, a Mnemósina como pastor, como moteada serpiente a la Deoida.

Ahora bien, al lado de este paralelismo general aludido es preciso pasar a comentar aspectos más concretos en algunos de los episodios recogidos, que confirmarán la hipótesis propuesta.

a) El episodio de Júpiter y Calisto - la fiel seguidora de Diana, a la que aquél posee disfrazado, en un primer momento para el engaño, de la propia 
Diana- no aparece en el mencionado relato de la Aracne ovidiana, pero si es recogido en Metamorfosis II 422-40, donde se mantiene el mismo matiz de trasgresión por parte de Júpiter (Metamorfosis v. 433: nec se sine crimine prodit) que la mención de Vinsauf (Poetria nova v. 621: Ut te fraudaret. Calixto, flore).

b) Pasemos ahora a la relación amorosa Júpiter-Ío. En nuestro autor (Poetria nova v. $621 \mathrm{~s}$.) se alude a una nube como recurso que utiliza el dios para conseguir a la muchacha: ... ni habría engañado a ĺo con una nube. Pues bien, de todos los grandes repertorios mitográficos, griegos o latinos, u obras de contenido esencialmente semejante, sólo en Las Metamorfosis ovidianas ${ }^{8}$ se precisa ese detalle de la nube como nueva estratagema del rey de los dioses en sus escarceos amorosos:

La habia visto (a ĺo) Júpiter cuando ella volvia de visitar al río su padre, y le había dicho: "Oh joven digna de Júpiter y que por tu lecho harás feliz a cualquiera, dirigete a las sombras de estos bosques profundos" (y le mostraba las sombras de los bosques) «... No huyas de mí.» Huía ella en efecto; ya había dejado atrás los prados de Lerna y los campos del Lirceo cuajados de árboles, cuando el dios cubrió la tierra en densa y extensa neblina, detuvo a la fugitiva y le arreható la virginidad.

c) En la referencia a la unión de Júpiter y Mnemósina hay un dato importante: en la mención de Vinsauf se especifica que el dios adoptó la forma de pastor para seducir a la Titánida; pues bien, curiosamente esta versión se nos ha trasmitido casi únicamente en el mencionado pasaje ovidiano ( $\mathrm{Me}$ tamorfosis VI 114$)^{9}$, dato éste que confirma nuevamente lo que venimos proponiendo.

d) También en la relación de Júpiter y Egina volvemos a encontrar un elemento de importancia: Vinsauf (Poetria nova v. 623s.) nos informa de que en esta ocasión el dios se trasformó en fuego para conseguir la unión amorosa, variante ésta que sólo encontramos en el tantas veces aludido pasaje ovidiano (Metamorfosis VI 113). La tradición más extendida afirma que Júpiter fulminó con su rayo al padre de la muchacha, el dios río Asopo, y de ahí es fácilmente explicable, como sugiere la crítica filológica, que Ovidio creó la novedad del cambio del dios en fuego, de donde lo tuvo que tomar Vinsauf a la luz al menos de los testimonios de que disponemos.

${ }^{8}$ Metamorfosis I 583ss.

${ }^{4}$ Cf. también Clemente de Roma, Serm. V. 14. 


\subsection{Mito de Ceres}

Dentro del mismo apartado de la descripción Vinsauf ofrece un ejemplo sobre un banquete, y en el arranque mismo de la prolija descripción se sirve del nombre de Ceres para aludir a los alimentos derivados de los cereales, en especial el trigo, o sea, el pan (Poetria nova v. 629-31):

Cuando el lecho acoge a los reyes y a los poderosos del reino, la imagen de la leche, la cultivada Ceres, da comienzo a las delicias de la mesa ...

En principio estaríamos ante el uso frecuente poético de Ceres por «trigo, pan», o Baco por «vino», etc. Pero el pasaje se vuelve más difícil de interpretar con esa mención de «la imagen de la leche», en aposición a la cual viene a continuación la mención de Ceres. Pues bien, vuelve a ser Ovidio quien, en dos pasajes de sus Fastos, nos da la pista para la explicación de la figura poética desarrollada por Vinsauf. En el primero ${ }^{10}$, al hablar de las diferentes clases de sacrificios cruentos, empieza aludiendo al del cerdo y de paso nos explica que en esa ocasión Ceres se regocijó de la muerte de ese animal, que se había revolcado en sus sembrados «lechosos en primavera». Pero el segundo pasaje ${ }^{11}$ es más explícito, al decirnos que la mies se vuelve blanca cuando madura, al contrario que la vegetación adscrita a Flora.

\subsection{Mito de Baco}

En el mismo pasaje en que hemos visto aparecer a Ceres, a continuación Baco es aludido sustituyendo así la mención específica del vino, con lo que estaríamos ante un uso prácticamente idéntico al visto respecto a Ceres (Poetria nova vv. 631-3):

... y el viejo Baco rejuvenece en oro

Tal vez el texto no merezca mucho más comentario, aunque de todas formas no debemos pasar por alto el paralelismo que observamos en un nuevo pasaje de

10 I 349-52: La primera en alegrarse con la sangre de una cerda tragona fue Ceres, que vengaba a sus mieses con la muerte merecida de la culpable. Pues se enteró de que sus sembrados, lechosos en primavera. los habia revolcado en sus tiernos surcos el hocico de una peluda cerda.

"Ovidio, Fastos V 355-8: Pero, ¿cómo es que, si en el festival de Ceres se regalan vestidos blancos, Flora se arregla con atavios multicolores? ¿Es porque la mies se pone blanca cuando maduran las espigas, y en cambio las flores acaparan todos los colores y vistosidades? 
Las Metamorfosis de Ovidio ${ }^{12}$, donde no sólo se da la identidad textual (in auro) sino que se coloca en el mismo segmento métrico de ambos hexámetros.

\subsection{Mito de Argos}

La alusión a Argos está presente en el apartado que se hace en la Poetria a la elocutio; más concretamente, dentro de la elocutio, en el capítulo que trata de los ornamentos estilísticos. Nuestro autor, después de hablar de la novedad en la expresión y de recomendar que es preciso colorear el discurso interna y externamente, pero en cualquier caso siempre con rigor ${ }^{13}$, pasa a continuación a dar un consejo (Poetria nova vv.753-6):

Por lo tanto, recuerda que no debes ser irreflexivo; por el contrario, se Argos en lo que puedas decir y con ojos vigilantes examina las palabras en el asunto propuesto.

Este Argos, claro está, es la bien conocida figura mítica famosa por poseer un sinnúmero de ojos ${ }^{14}$ distribuidos por todo el cuerpo, lo que lo convertían en el vigilante idóneo y, con este cometido, lo encontramos interviniendo en diferentes relatos.

\subsection{Alejandro Magno}

Como ya hemos apuntado más arriba, Vinsauf a veces mezcla -incluso en un mismo pasaje-- personajes míticos con otros indiscutiblemente históri$\cos$, lo que pone de manifiesto que en ese momento los unos y los otros estaban incluidos en un mismo bloque de figuras modélicas, que se mantenían como ejemplo sin necesitar de una certificación de validez histórica o no.

Un caso especialmente interesante es la anécdota que cuenta sobre Alejandro Magno. La referencia está incluida en la explicación que se da sobre el adorno fácil dentro de los adornos estilísticos. La introducción de Vinsauf es la siguiente (Poetria nova vv. 1098-100):

12 VI 488-9: ... un regio menú es servido en las mesas y Baco en el oro.

$13 \mathrm{Vv}$. 742-4: Sea breve o largo, el discurso siempre debe colorearse interna y externamente, pero distinguiendo el color con un orden distinto.

14 Las diversas tradiciones divergen sobre el número concreto de ojos, pero ese punto no tiene relevancia en nuestro trabajo. 
Si el discurso quisiera ser leve y de un bello adorno, elimina todos los adornos de estilo solemne y emplea los de estilos sencillos, pero de una sencillez tal que no asuste los oídos por su rudeza.

A su vez, dentro de esta fórmula retórica, el ejemplo del que ahora nos ocupamos está contenido entre las variantes de la significación como ejemplo de similitud, es decir, pone en relación comparativa, con fines de hacerlo creíble, todo fenómeno semejante (Poetria nova vv. 1569-80):

Comparado así el asunto, nada más añado. Mejor observa un ejemplo contenido en este discurso variado: Cuando Alejandro Magno hizo la guerra a Atenas, ninguna negociación para establecer la paz le agradó, excepto que los hombres sabios de la ciudad fueran entregados como rehenes. El más prudente de ellos respondió a eso con estas palabras: «Una vez, el lobo hizo la guerra al pastor. De ambas partes se trató sobre la paz; pero ninguna fórmula de paz agradó al lobo, excepto que como rehén y garantía de amistad le fuera entregado el guardián del rebaño. Hecho esto, antes fue un enemigo tímido, después más seguro». Dicho esto, guardó silencio.

Esta cita demuestra la difusión que existía de la historia de Alejandro Magno en toda la época medieval. Concretamente, este episodio aparece recogido, entre otras fuentes, en una obra muy anterior, del siglo III de nuestra era, en la Vida y hazañas de Alejandro de Macedonia del llamado Pseudo Calístenes. En II, 2 se describe la petición de Alejandro de que le fueran entregados los diez mejores oradores, así como los discursos que éstos (Esquines, Démades, Demóstenes, Lisias, ...) mantuvieron frente a la exigencia de Alejandro. Pero, curiosamente, dentro del discurso de Démades hay una alusión que está en clara relación con el pasaje mencionado de Vinsauf, lo que hace ver que, efectivamente, en la tradición tan extendida y diversa de esta biografía de Alejandro se introdujo esta anécdota, sobre la que Vinsauf nos ofrece una versión más detallada:

No obstante, quiero advertiros esto previamente, atenienses, que muchas veces diez perros con sus valientes ladridos salvaron por sí solos el rebaño entero de las ovejas que se hallaban atemorizadas ante los lobos.

\section{TERCER TIPO: ALUSIÓN TÓPICA}

Por último, vamos a adentrarnos en el tercer tipo de ejemplos dentro de la clasificación que hemos establecido. Se trata de ejemplos mucho más breves 
que los dos anteriores, ya que son simplemente alusiones tópicas a una característica bien determinada de diversos personajes mitológicos o históricos en la tradición cultural. Suelen ser ejemplos que se repiten en varias ocasiones. Queremos, además, hacer una indicación importante: en casi todos los casos estos ejemplos no aparecen solos, sino que se presentan concatenados unos con otros.

En este último apartado no vamos a seguir una exposición individual de cada personaje, sino que procederemos a una serie de reflexiones generales que nos expliquen su uso.

En este sentido, debemos comenzar comentando que se trata de simples alusiones más o menos estereotipadas a personajes casi siempre ampliamente conocidos, y cuyo rasgo característico está perfectamente definido en la tradición. Así, se menciona a Paris como representante de la belleza, a Venus como denominación abstracta del amor, a Pirro por su vigor o energía vital ${ }^{15}$, a Orfeo por su bien conocido arte en cantar al son de la lira ${ }^{16}$. En el caso de Ulises perfila Vinsauf una definición más exacta al contraponer la fuerza física (vir) al poder de la inteligencia (mens), adjudicando al héroe homérico una hegemonía indiscutible en la segunda, en lo cual sigue igualmente una tradición que arranca de los primeros momentos. En algún caso tal vez la caracterización resulta un tanto imprecisa, como podría ser el caso del héroe ateniense Teseo, al que atribuye sin más precisiones la cualidad del amor ${ }^{17}$. Finalmente, en ocasiones, y dentro de diversas finalidades retóricas, nos define a ciertos héroes por lo contrario, y así vemos cómo irónicamente califica de corde ferocem ${ }^{18}$ a Eneas, que es el héroe pius por antonomasia; o a Hipólito de petulantem ${ }^{19}$, cuando representa la idea de la contención y la honestidad frente a las desvergonzadas tentativas de Fedra. Pero, en cualquier caso, ya sea en su empleo correcto ya sea en el uso de la antífrasis, Vinsauf hace gala de un conocimiento oportuno de estas grandes figuras del mundo mítico grecolatino.

Pero no es menos cierto que también menciona a otros personajes que podriamos considerar de segundo rango, lo que habla a favor de una cierta profundidad en su conocimiento de la mitología, puesto que la alusión de pasada significa familiaridad con el referente utilizado. Éste tal vez sea el caso de Tersites, Partenopeo, Capaneo, Tifis o Automedonte, héroes con una presencia menor en el relato mítico pero a los que nuestro autor califica tan acertada-

15 En el v. 1780 se utiliza el sustantivo vigor, y en 1812 el verbo viget.

16 Poetria nova v. 1813: modulatur.

17 Poetria nova v. 1813: amat ut Theseus.

18 Poetria nova v. 936.

19 Poetria nova v. 938. 
mente como a las grandes figuras más arriba mencionadas. Y todo esto nos va llevando a concluir que Vinsauf, aunque textualmente parece seguir de cerca de Ovidio, y en especial sus Metamorfosis, no por ello desconoce otras áreas de la Mitología ausentes de esa obra, incluso del propio Ovidio.

También en este apartado de las alusiones tópicas recurre a personajes históricos: Creso, Cicerón, César, Nerón y Catón son citados como modelos de una determinada virtud o rasgo personal, y siempre en la línea de interpretación que la tradición nos los ha hecho llegar. Y, como ya hemos visto, lo hace en mezcolanza con las figuras estrictamente míticas, lo que confirma la sugerencia que ya hacíamos más arriba, cuando aludíamos a este mismo proceder en referencias más elaboradas. 